\title{
Urgences
}

\section{Urgences " pair " ou " impair ", c'est du neuf ! Jean Cossette}

Numéro 9, 1er trimestre 1984

URI : https://id.erudit.org/iderudit/025130ar

DOI : https://doi.org/10.7202/025130ar

Aller au sommaire du numéro

Éditeur(s)

Urgences

ISSN

0226-9554 (imprimé)

1927-3924 (numérique)

Découvrir la revue

Citer ce document

Cossette, J. (1984). Urgences " pair " ou " impair ", c'est du neuf ! Urgences, (9),

5-6. https://doi.org/10.7202/025130ar

Ce document est protégé par la loi sur le droit d'auteur. L’utilisation des services d’Érudit (y compris la reproduction) est assujettie à sa politique d'utilisation que vous pouvez consulter en ligne.

https://apropos.erudit.org/fr/usagers/politique-dutilisation/
Cet article est diffusé et préservé par Érudit.

Érudit est un consortium interuniversitaire sans but lucratif composé de l’Université de Montréal, l'Université Laval et l'Université du Québec à Montréal. Il a pour mission la promotion et la valorisation de la recherche. https://www.erudit.org/fr/ 


\section{URGENCES “PAIR" OU “IMPAIR", C'EST DU NEUF!}

Depuis quelques temps dans les couloirs du quartier général d'Urgences, on ne jure plus que par le "pair" et "l'impair". En effet, depuis l'adoption de notre nouvelle politique qui veut que chaque numéro pair d'Urgences en soit un thématique ou spécial, nos collaborateurs ont acquis très rapidement cette vision à long terme qui leur permet de demeurer à la fine pointe de la nouveauté littéraire.

Notre premier numéro spécial portait sur la littérature jeunesse. Depuis son lancement en novembre 1983, ce numéro ne cesse de nous attirer les éloges des milieux spécialisés et du grand public. Ce succès nous encourage vivement dans la poursuite de cette politique qui se veut diversifiée et "new look". Si le numéro 8 permettait à nos lecteurs de se renseigner sur "La littérature enfantine à l'école", par le biais de notre nouvelle chronique, le numéro 9 présente un atout très important au culturel en Région 01, La Savoyane.

Dans ce numéro impair ou régulier d'Urgences, nous accueillons comme auteure invitée, Pauline Cadieux. Elle viendra allumer une autre petite lampe dans la fenêtre de plus en plus éclairée de la littérature est-québécoise. De plus, sans devenir une multinationale, notre revue se permet de présenter des écrivains d'outre-frontière, en l'occurence Andréa Moorhead des Etats-Unis et Jorge Etcheverry, originaire du Chili. Nos autres collaborateurs pour ce numéro spécial "non-thématique" viendront, le cas échéant, renouer avec nos fidèles lecteurs ou grossier les rangs déjà imposants des élus.

On ne saurait trop insister sur la valeur des textes "inédits" que nous publions. De ce fait, chaque numéro d'Urgences qu'il soit pair ou impair, se veut 
neuf. Nous sommes fier de compter parmi nos auteurs déjà retenus un Michel Savard, Prix du Gouverneur général 1983, un Jean-Marc Cormier et un Denis Saint-Yves, respectivement lauréats du Prix du Salon du Livre de Rimouski 1981 et 1982, sans compter tous ces auteurs de qualité qui font leur marque de belle façon et qui sont en voie de se frayer un curriculum enviable au palmarès de nos lettres québécoises.

En cette année 1984, I'urgence pour vous chers lecteurs, chères lectrices, consiste à poursuivre vos encouragements, votre soutien et... votre abonnement. Sans vous, il nous serait difficile de progresser dans cette recherche humaniste car, comme le disait si bien Charles du Bos dans ses Approximations:

“La littérature n'est rien d'autre que la gamme entière de toutes les émotions humaines dont chacune, grâce à tel ou tel génie, a trouvé son impérissabble expression".

Jean Cossette pour le Comité de direction 